Agro-Science Journal of Tropical Agriculture, Food, Environment and Extension Volume 10 Number 1 January 2011 pp. $17-26$

ISSN 1119-7455

\title{
INDICATORS OF CLIMATE CHANGE IN THE DERIVED SAVANNAH NICHE OF NSUKKA, SOUTH-EASTERN NIGERIA
}

\author{
Uguru, M. I. Baiyeri,K. P. and Aba S. C. \\ Department of Crop Science, University of Nigeria, Nsukka, Nigeia.
}

\begin{abstract}
To track changes in our climate over the past 40 years, three important weather elements namely; temperature, rainfall and relative humidity were analyzed. The results obtained revealed that there is a trend towards warmer temperatures, fluctuating rainfall distribution pattern and reduced relative humidly in the derived savanna ecological belt. The period, 2005-2010, represents the six warmest years in the past four decades in the derived savanna ecology. The bi-modal rainfall pattern is still in place but with a discernable shift of the second peak from September to October from 2001 to 2010. These glaring changes have implications on the development of Agriculture and preservation of biodiversity. Therefore, capacity building among native researchers to conduct locally relevant, policy-oriented research needed to support cogent decisions about adaptation and mitigation, and to provide reasonable options for the support structure required to facilitate and implement the research is imperative.
\end{abstract}

Key words: climate change, agriculture, derived savannah, Nigeria

\section{INTRODUCTION}

In recent times, 'climate change' has become a very popular jingle among environmentalists, researchers, policymakers, climatologists and the politicians alike. Most often, media around the world are awash with stories of climate change, which has become the buzzword in almost every contemporary discourse. Several development agencies, including faith-based organizations are actively engaged in programming for climate change. Experts have at various times declared climate change the greatest human tragedy in history, and the greatest threat to the sustainability of our ecosystems and coexistence (Gleik et al., 2000).

Climate change is defined as a longterm shift in the climatic pattern of a specific location, region or planet measured by changes in features associated with average weather components, such as temperature, wind patterns and precipitation (Warrick and Barrow, 1991). Consequent to these changes includes global warming, i.e., increased average temperature of the earth, frequent hurricanes, droughts and floods of varying intensities.

Climate change occurs when the climate of a specific area or planet is altered between two different periods of time. This could occur when there is a change in the total amount of the sun's energy absorbed by the earth's atmosphere and surface. Climate change also happens when there is a change in the amount of heat energy from the earth's surface and atmosphere that escapes into space over an extended period of time. Such changes can involve both changes in average weather conditions and changes in how much the weather varies around these averages.

These changes, according to the report of the United Nations' Intergovernmental Panel on Climate Change (IPCC, 2001) can be caused by natural processes like volcanic eruptions, variations in the sun's intensity, or very slow changes in ocean circulation or land surfaces which occur on time scales of decades, centuries or longer. However, human activities are by far the major cause of climate change through the continuous release of greenhouse gases and aerosols into the atmosphere, by changing land surfaces, and by depleting the stratospheric ozone layer.

So much awareness, claims and counter-claims about global climate change have been made by researchers worldwide (AERC, 2007) often with paucity of factual evidence to substantiate the fact and clarify the existing doubt. Besides, African scientists have consistently relied on literature information from the developed world to draw inferences on climate change and its effects on countries in Africa. This has created an information gap between many of the scientific claims and the existing realities in many African countries.

In this paper, we have summarized a forty-year weather data (1971 - 2010) from the Faculty of Agriculture, University of Nigeria, 
Nsukka meteorological station to track changes in our climate in the last four decades. This will form a base-line record in our contemporary ecological niche towards the actualization of the global quest for a mitigation and/or adaptation approach over the worrisome environmental threat.

Study location: This study was conducted at the Department of Crop Science, Faculty of Agriculture, University of Nigeria, Nsukka, Enugu state, Nigeria. Nsukka is a tropical derived savannah niche located on latitude $6^{0} 51^{\prime}$ $\mathrm{E}$, longitude $7^{0} 29^{\prime} \mathrm{N}$ and at an altitude of $400 \mathrm{~m}$ above sea level.

Data collection and analysis: A fortyyear (1971-2010) observational data set comprising daily rainfall $(\mathrm{mm})$, maximum daily temperature $\left({ }^{0} \mathrm{C}\right)$ and relative humidity $(\%)$ obtained from the Faculty of Agriculture meteorology station were summarized in visual graphic displays using GGE biplot (Yan and Kang, 2003) software and excel spreadsheet.

\section{RESULTS AND DISCUSSION}

The bimodal rainfall pattern prevalent in the tropics is evident in Figure 1. The first peak (point A) occurred in June, followed by a drop between July and August (otherwise known as August break), while the second peak (point B) occurred in September. The first peak of rainfall however, occurred in May from 1971 to 1980, and in July from 1981 to 1990 . Worthy of note is the discernable shift of the second peak of rainfall from September to October within the last decade (2001-2010). This shift is a virtue that can be exploited as it implies a prolonged growing season for farmers. However, this could alter the ecology of the derived savannah belt with some implications on biodiversity at the long run. Another important feature in Figure 1 is the drop in rainfall amount received in February, depicting a delay in commencement of rains in the last three decades. The rainfall amounts recorded beyond September showed consistent decline over the past four decades (see the trend at point B).

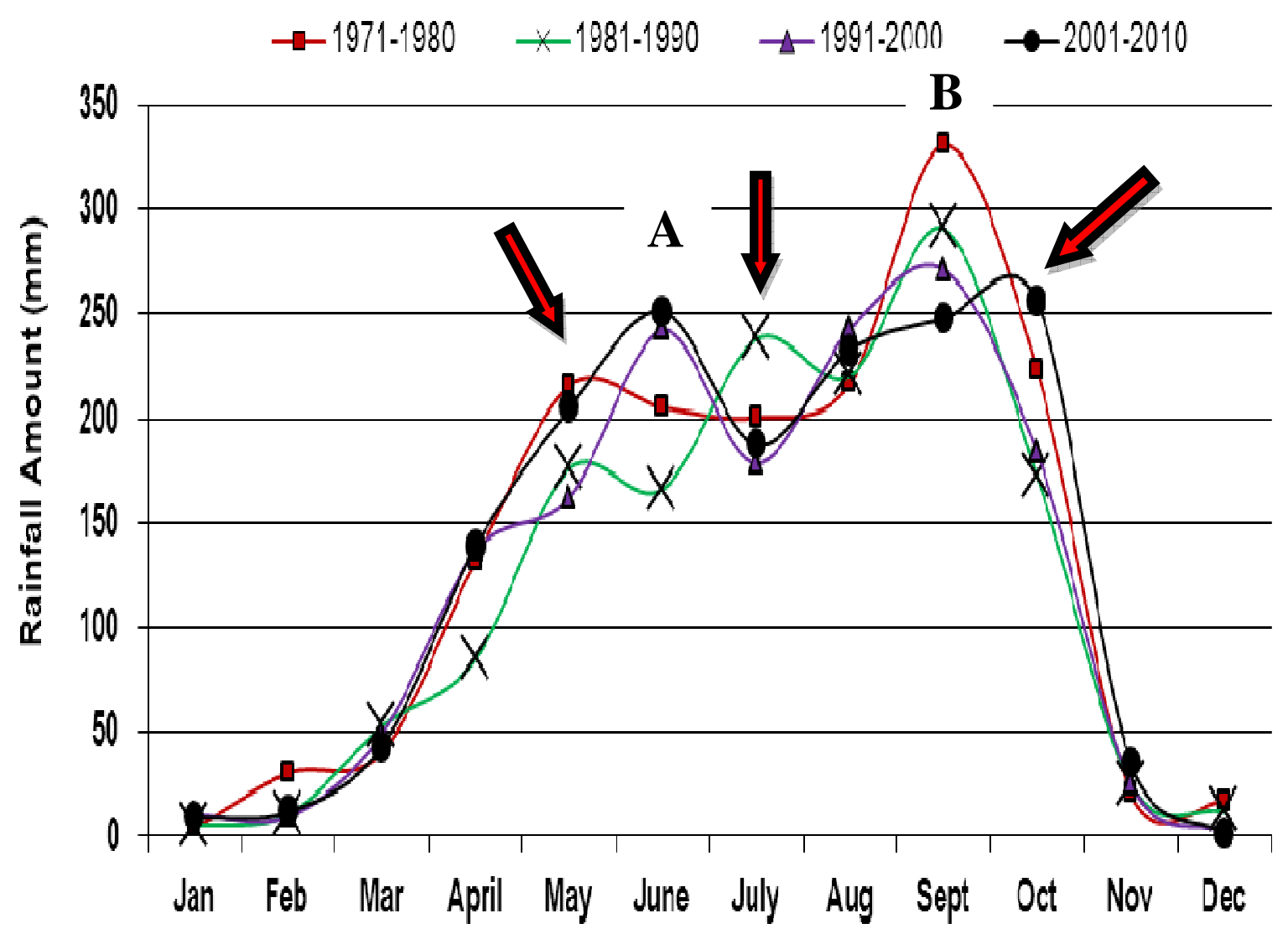

Figure 1: Rainfall distribution pattern (1971 to 2010) 
The deviations from the mean rainfall amount $(\mathrm{mm})$ in Figure 2 suggest obvious fluctuations over the years. Rainfall amount was particularly low $(<1000 \mathrm{~mm})$ in 1983 , and this is somewhat similar to the amounts recorded in 1977, 1992, 1996 and 2001. Beyond 2003, annual rainfalls were consistently higher than the overall mean value $(\approx 1555 \mathrm{~mm})$ recorded over the forty-year period. Excessive precipitation is deleterious to the fragile tropical soils and renders many crops vulnerable to diseases and waterlogging

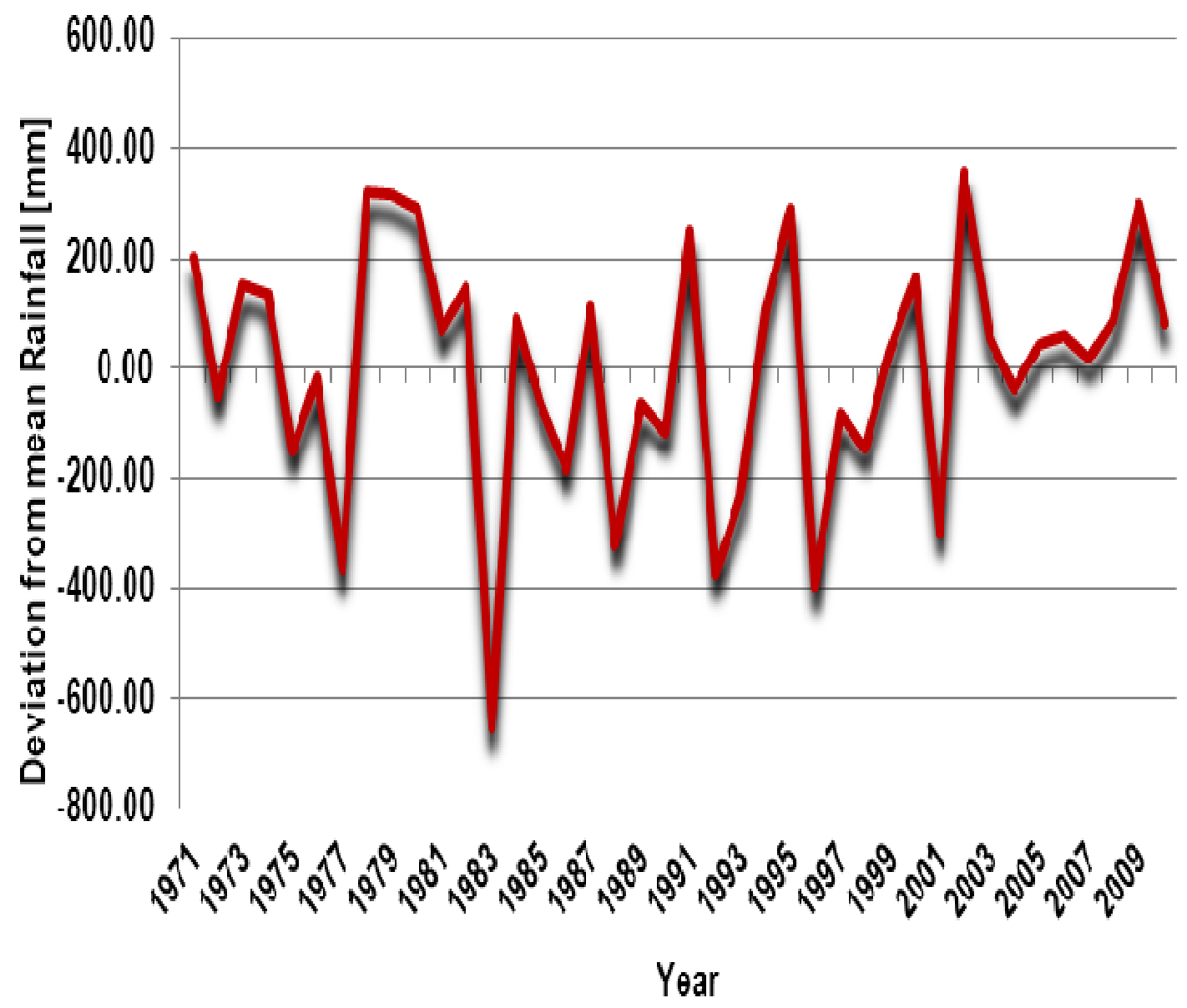

Figure 2: Deviation from mean Rainfall amount $(1554.65 \mathrm{~mm} / \mathrm{annum})$ measured from 1971 to 2010 
The relative humidity curves (Figure 3 ) followed similar trends as the rainfall over the last four decades, but for the slight irregularities observed between March and April. Relative humidity dropped considerably from 2005 to 2010, but was somewhat higher than normal around December within the same period. The deviations from the annual relative humidity mean (Figure 4) were very irregular, with the lowest values recorded in 1981, 1983 and 1988. A progressive drop in relative humidity was observed after 2005 in contrast to the amounts of rainfall recorded in the same period.

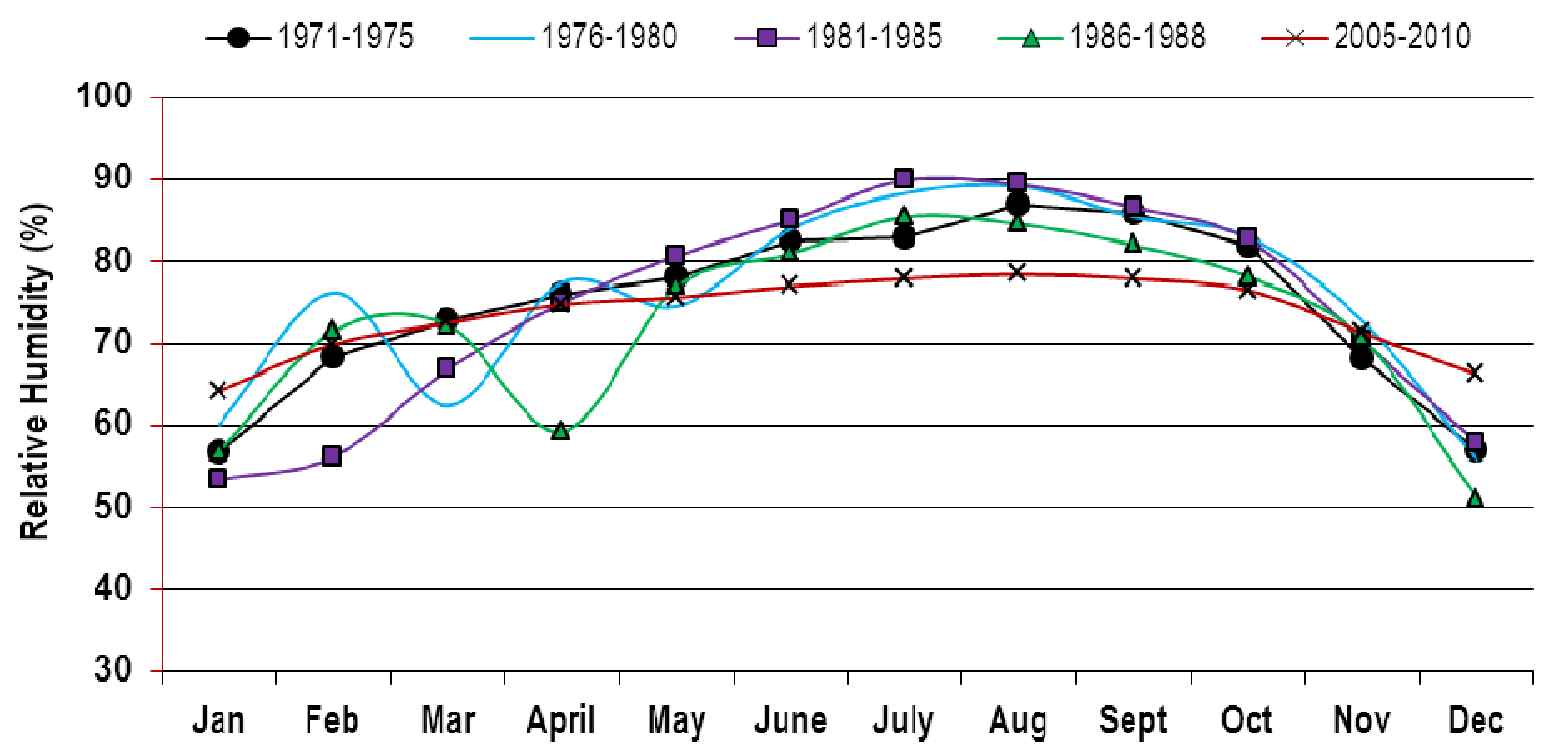

Figure 3: Monthly relative humidity (\%) from 1971 to 2010

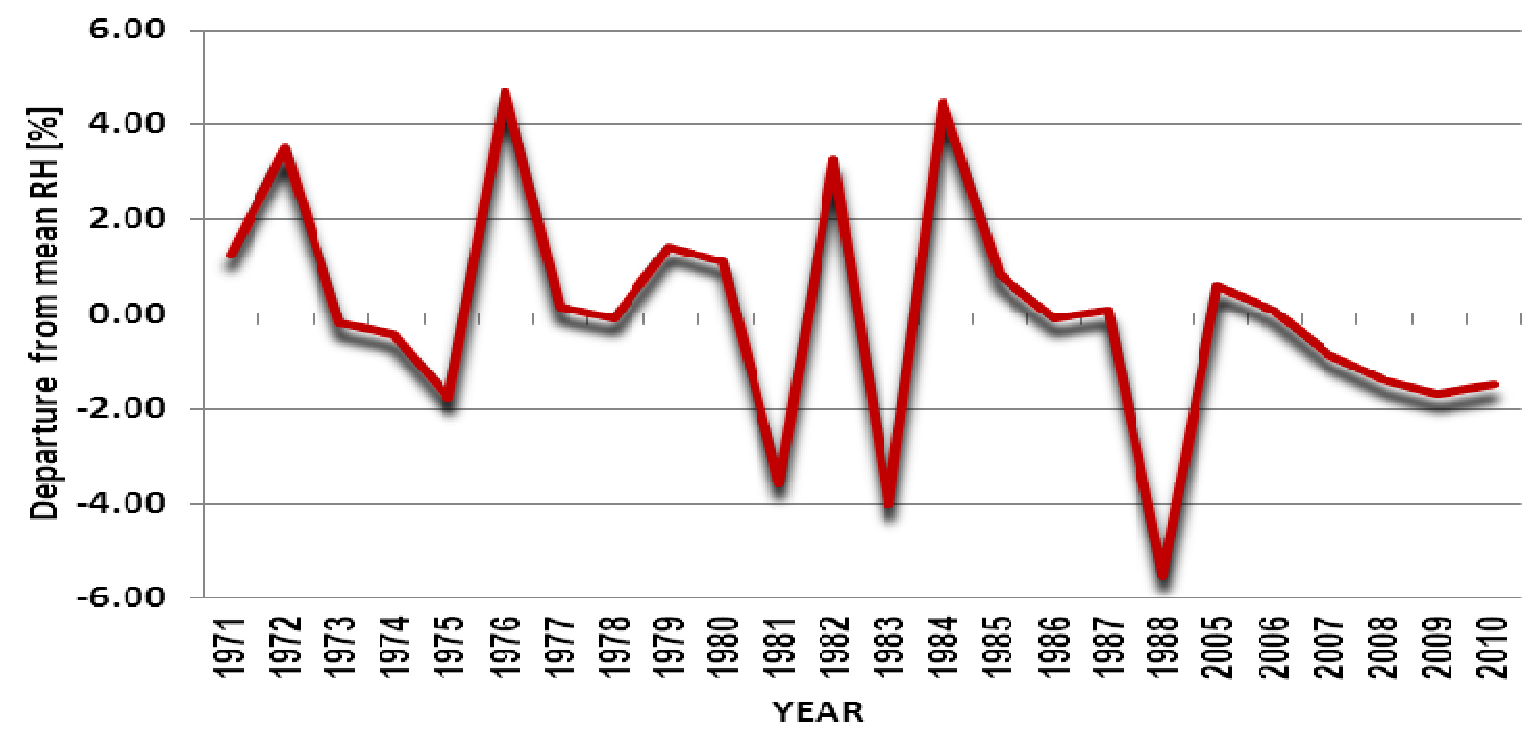

Figure 4: Deviation from the mean Relative humidity value (74.29 \%) measured from 1971 to 2010 


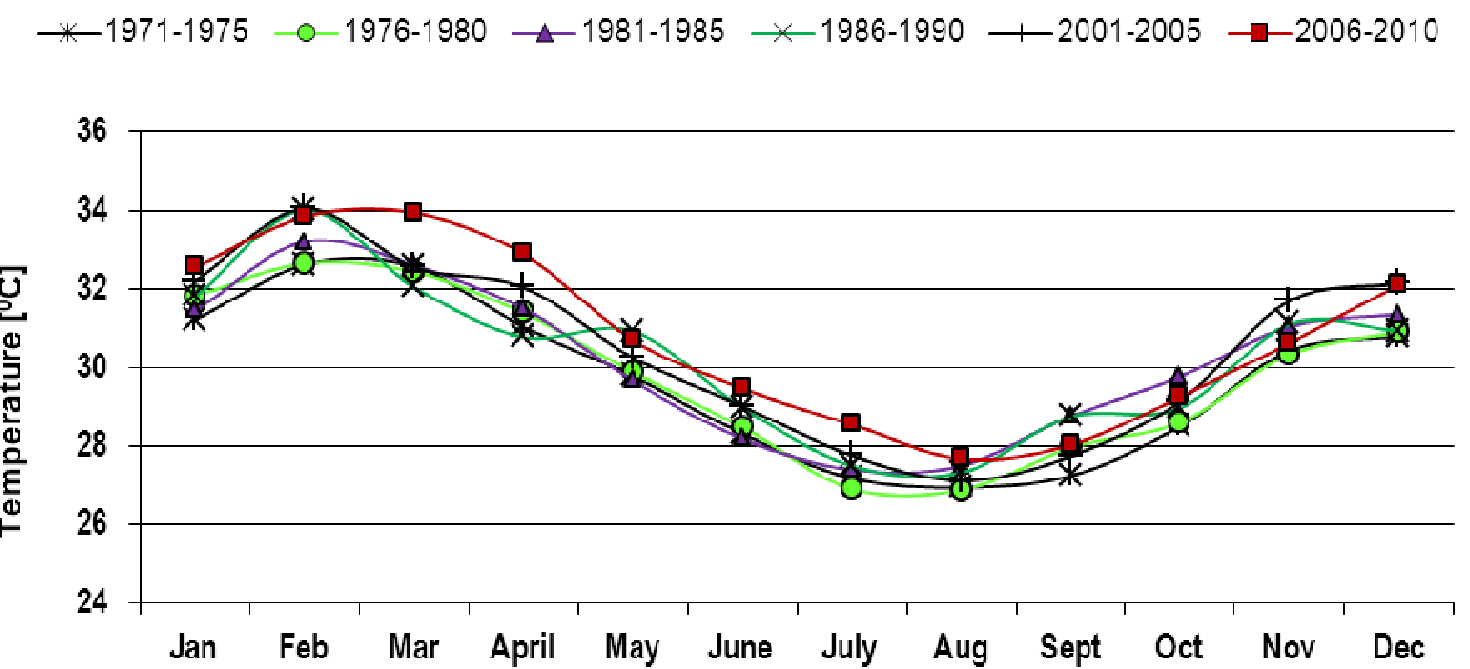

Figure 5: Mean monthly temperature $\left({ }^{0} \mathrm{C}\right)$ trend from 1971 to 2010

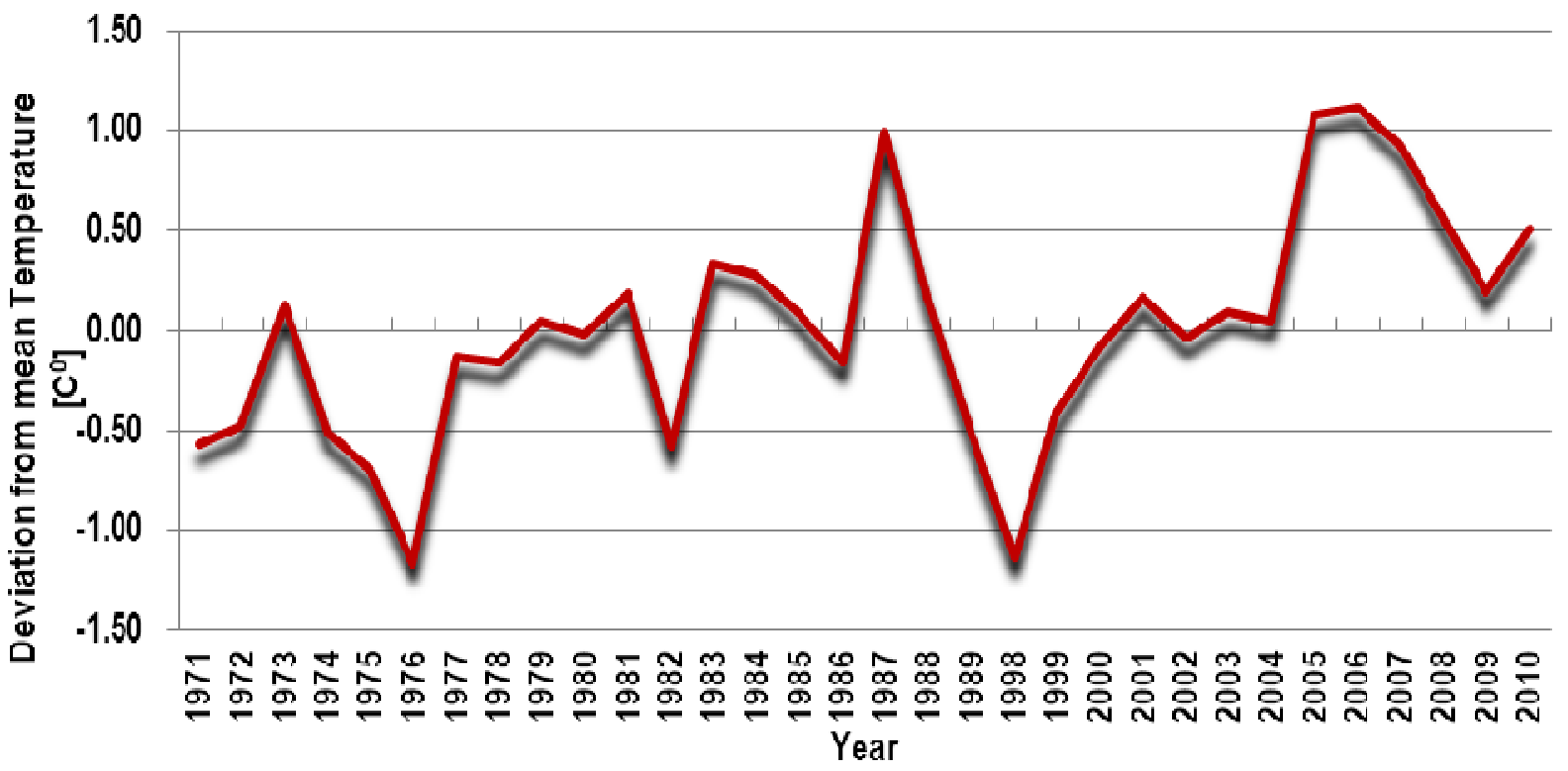

Figure 6: Deviation from the mean Temperature $\left(30.15 C^{0}\right)$ measured from 1971 to 2010 

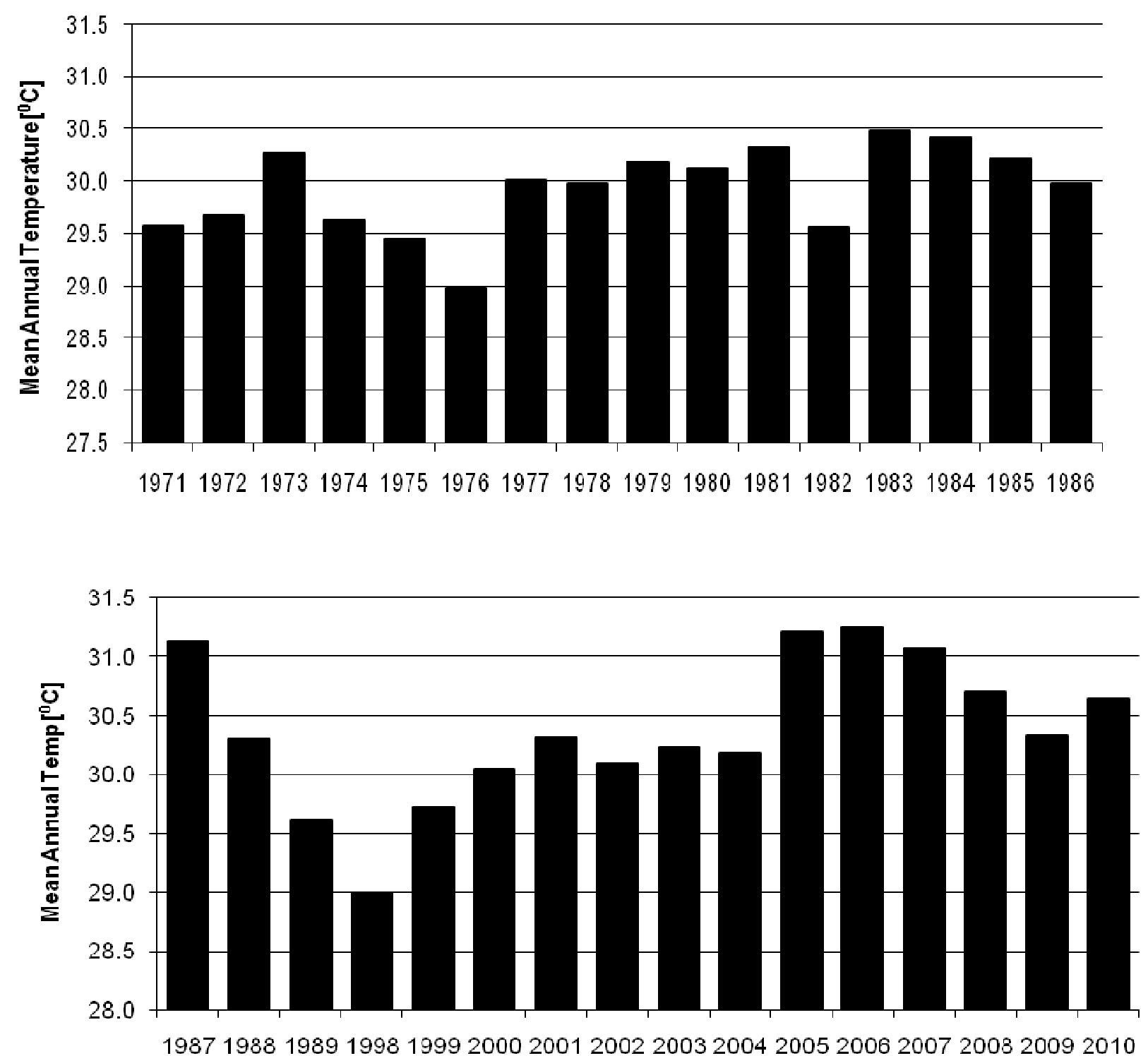

Figure 7: Mean Annual Temperature $\left[{ }^{0} \mathrm{C}\right]$ from 1971 to 2010

The mean monthly temperature values over the last four decades are shown in Figure 5. The monthly data allows for the investigation of seasonal trends in temperature. The trend appears to be consistent over the years. However, higher temperatures were recorded from 2006 to 2010 between March and August. A similar rise was observed from 2001 to 2005 during the harmattan months of October to December.

The deviations from the mean temperature from 1971 to 2010 are shown in Figure 6. Annual average temperature for the derived savannah ecology varied considerably. For example, note the cooler years in 1976, 1982 and 1998, and the relatively warmer years in 1987, 1988 and 2005, and beyond. The last five years (2005-2010) appears to represent the longest stretch of warmest period in the derived savannah belt in the last four decades. Even more striking is the $1^{0} \mathrm{C}$ increase in 1987, 2005, 2006 and 2007. Although a slight drop in temperature was recorded in 2009, there was an obvious evidence of rise in annual temperature in 2010 (Fig. 7).

Each of the biplots (Figures 8-11) explained $84.2 \%$ of the total variations in annual rainfall, temperature and relative humidity over the last four decades. These biplots revealed the yearly trend or pattern of the three weather variables evaluated. Figure 8 indicated that temperature was the most inconsistent 
(i.e., the most varied element) over the forty-year period, followed by rainfall. Relative humidity also showed some disparities over the years, but was the most consistent during the study period.

Figure 9 shows distinct variations in temperature, rainfall and relative humidity over the forty-year study period. The years positioned at the vertexes of the polygon recorded the highest values with respect to temperature, rainfall and relative humidity. The year, 2006 had the highest temperature and this was very similar to the temperatures recorded in 1987, 2005 and 2007. These were followed by 2008, 2010 and 2009 in that order. The coolest year (located at the opposite vertex) was 1976 , followed by 1998 , 1972, 1982, 1975, 1971 and 1989. These years were also the most humid, having high relative humidity. The rainfall was highest in 1979, but relatively similar to the values for 2002, 1980, 1995 and 1991. The year, 1983 located at the vertex directly opposite the rainfall segment witnessed the lowest amount of rainfall, and all the years within that segment (1988, 1996, 1992, 1977, and 2001) had relatively low values in all the three climatic variables. The year, 2004 had the overall average for the three weather elements under study, as it is at the center of the polygon. Also located around the biplot origin are 1990, 1985 and 1997 with all other years within the central concentric circle oscillating around the mean values for temperature, rainfall and relative humidity.

The average tester coordination (ATC) view in Figure 10 identified the year, 2009 as an 'ideal year', having relatively high performance in all the three climatic elements studied. The double-edged arrow line crossing the ATC line, divides the years into two distinct groups - the low and high performers. All the years located above the perpendicular double-edged line (towards the right) had above-average performance for temperature, rainfall and relative humidity. Correspondingly, all the other years below the perpendicular line (towards the left) had lower-thanaverage values in all the three climatic elements studied.

Worthy of note is that all the years beyond 2000 (with the exception of 2001) had higher-thanaverage performance similar to 2009 (Figure 10), signifying an upward shift (or rise) in weather elements in the last decade. The longer the vector lengths connecting each year to the average tester coordination view, the more the year's performance differed from the overall mean.

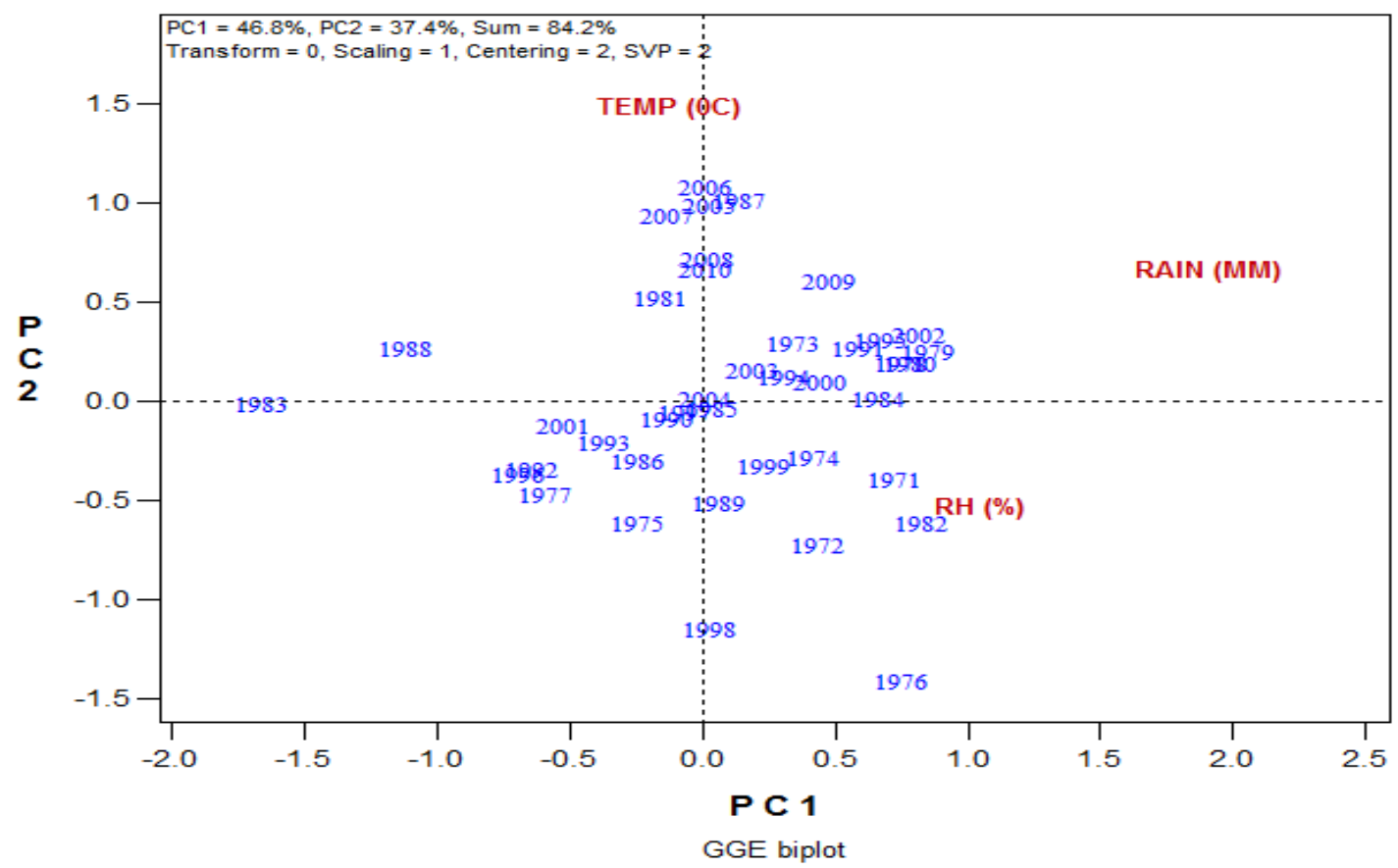

Figure 8: Biplot diagram showing the Annual Rainfall, Temperature and Relative Humidity from 1971 to 2010 


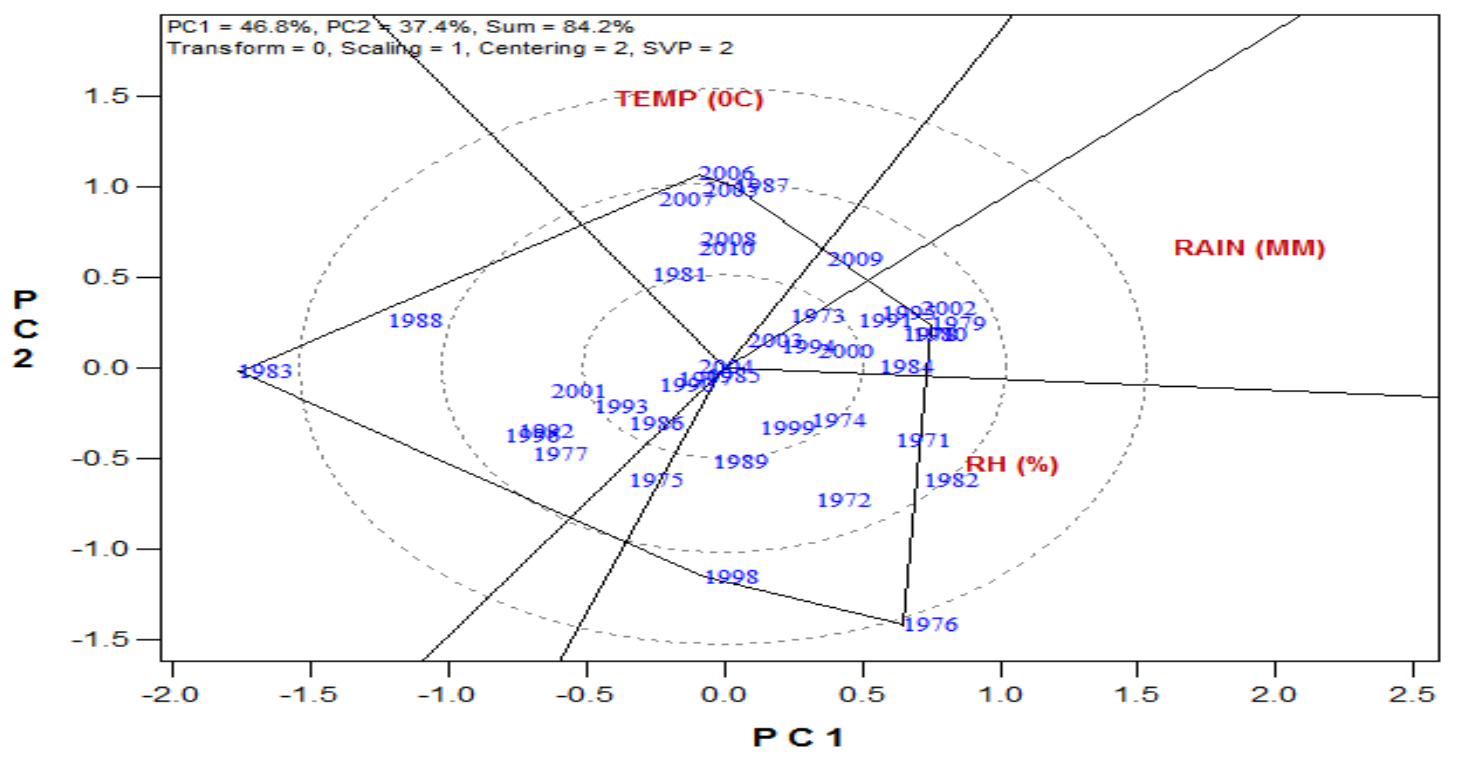

Which wins where or which is best for what

Figure 9: Biplot diagram grouping the annual performances in Rainfall, Temperature and Relative Humidity from 1971 to 2010

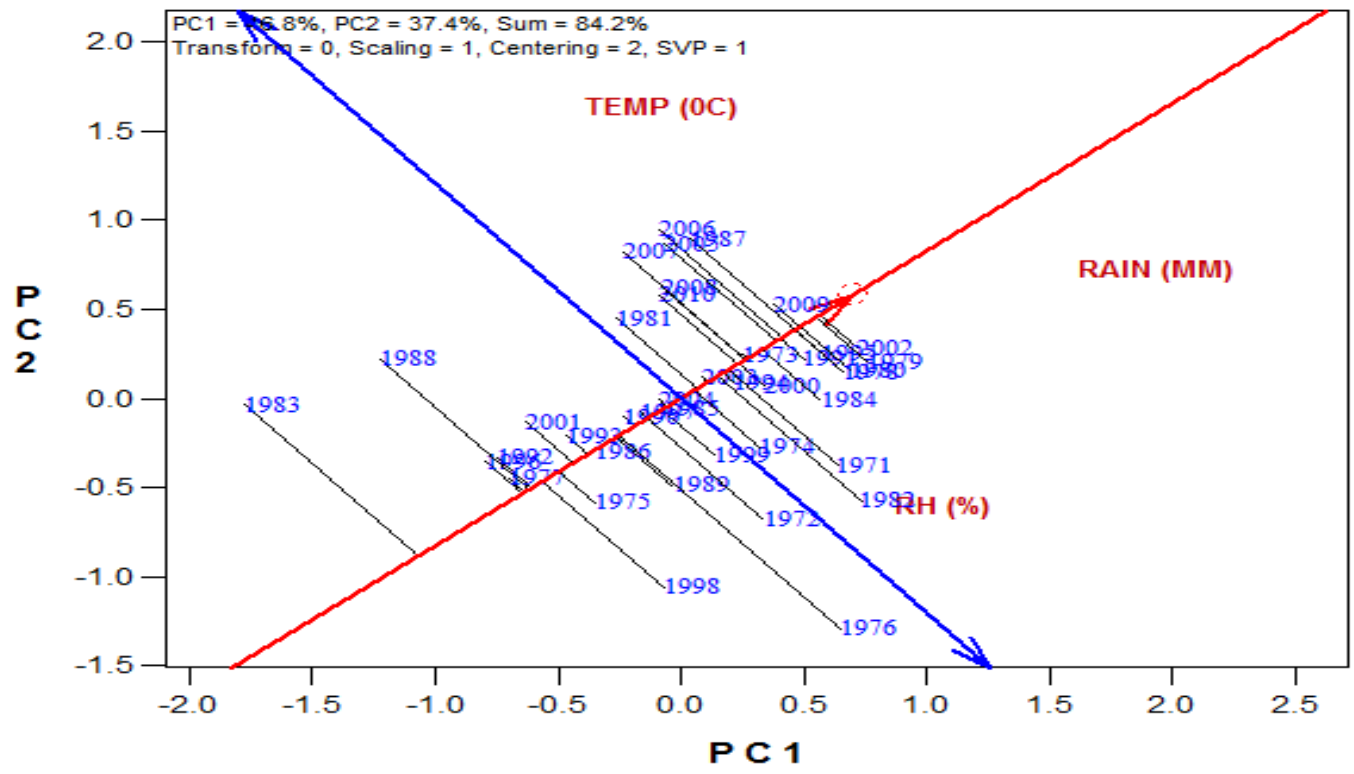

The Average Tester Coordination view

Figure 10: Biplot diagram showing the relationships in annual Rainfall, Temperature and Relative Humidity from 1971 to 2010 
Uguru, M. I. Baiyeri,K. P. and Aba S. C.

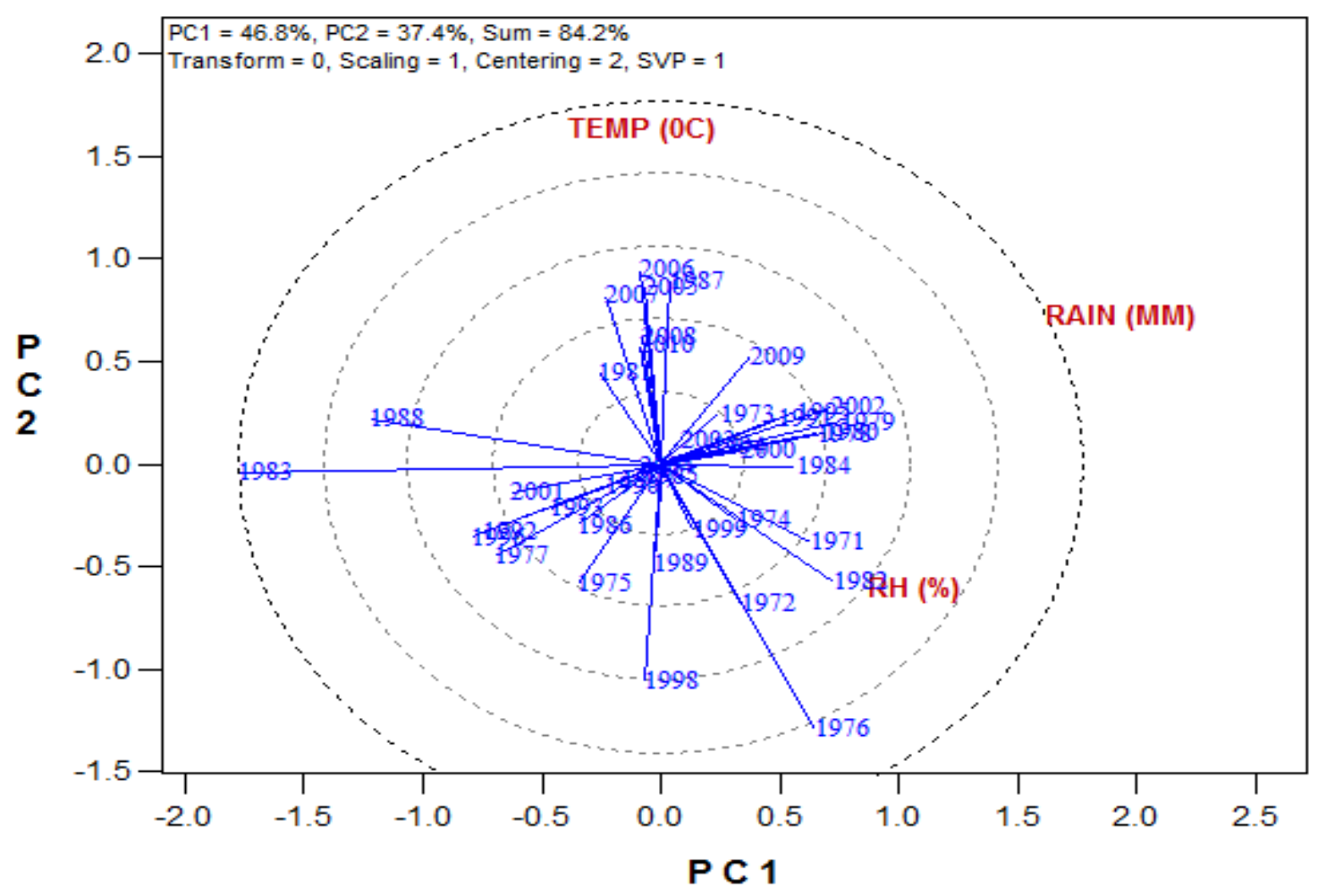

Relationship among entries

Figure 11: Biplot diagram showing the relationship among entries (years) as regards to annual Rainfall, Temperature and Relative Humidity from 1971 to 2010

Figure 11 is a vector view biplot showing the existing relationships among the years. The shorter the distance between two vector lengths, the closer the relationship between them. The years, 1981, 1987, 2005, 2006, 2007, 2008 and 2010 formed a close cluster of years with high temperature. A similar cluster of years between 1984 and 2009 (comprising 1973, 1978, 1979, 1980, 1984, 1991, 1994, 1995, 2000, 2002, 2003 and 2009) exists as years of high rainfall amount. Relative humidity was rather similar in 1971, 1972, 1974, 1976, 1982 and 1999, forming a close cluster of year vectors. All the other years located between 1988 and 1998 were poor in the three climatic variables evaluated.

The indicators analyzed in the present study have revealed that the climate of the derived savannah ecology of Nigeria is changing. Six out of the seven warmest years since 1971 occurred between 2005 and 2010, and most of the years in the last decade (2001 - 2010) recorded aboveaverage temperatures, confirming a temperature rise in the derived savannah belt. This is in line with earlier reports that the ten warmest years in global meteorological history have all occurred in the past 15 years, and that the $20^{\text {th }}$ century has been the warmest globally in the last 600 years (Brohan et al., 2006). The driest years also occurred within this range probably due to increased evapotranspiration following the rise in temperature.

It is evident from this study that, (i) there is a rise in temperature in recent years - warmer temperatures being recorded between 2005 and 2010, (ii) there is a paradigm shift in rainfall pattern (commencement, cessation, distribution and amount) in the last few decades, and (iii) there is a considerable drop in relative humidity in the last decade. 
The few indicators of climate change presented in this report namely; temperature, rainfall and relative humidity have shown that the derived savannah ecology has warmed over the past 10 years and that the rate of warming has remained consistent over the past 5 years. Of particular interest for the region is that much of the warming is recorded from January to April during which there is a drop in rainfall amount and relative humidity. These would interfere with the planting time-table of farmers in the derived savannah ecology. Fruit trees that bloom during this period may experience significant flower or premature fruit abortions if they are not supported with supplemental irrigation.

Extreme weather events, such as drought and forest fire devastations in Kenya and Ethiopia or floods that rendered more than 100, 000 people homeless in Mozambique, Botswana and South African, may not have been experienced in Nigeria but some of the indicators of discernable change in our climate have been diagnosed in the present study.

It is now imperative to urgently build capacity of African researchers to conduct rigorous, locally relevant, policy-oriented research into the consequences of climate change, and the mitigation and adaptation initiatives being promoted at the global level. Mitigation and adaptation are the two principal ways of dealing with the threat of climate change (Ozor et al., 2010). We can mitigate by reducing the greenhouse gas emissions into the atmosphere and enhanced sequestration through plantation development. Substantial efforts should be made to protect agriculture which is the primary industry of Nigeria. Adjustments in this direction would involve breeding to produce new crop and animal breeds with innate elasticity to tolerate the changing climate.

The causes of climate change are global, but the impacts are local. The necessary adjustments to cope with the challenges of climate change should be made. Nigeria can utilize the laudable initiative of the Open Society Foundations (OSF) of the United States of America in institutionalizing a trans-disciplinary climate change adaptation capacity building initiative.

\section{REFERENCES}

AERC (2007) Climate change. (Ajakaiye O., ed.) The African Economic Research Consortium. Research news 10, 41pp.

Brohan, P., J.J. Kennedy, I. Harris, S.F.B. Tett and P.D. Jones (2006) Uncertainty estimates in regional and global observed temperature changes: a new dataset from 1850. J. Geophysical Research 111, D12106, doi:10.1029/2005JD006548

Gleik, P.H; R.M. Adams and R.M. Amasino (2010). Climate Change and the Integrity of Science. Science, 328: 689-691.

IPCC (2001) Intergovernmental Panel on Climate Change. The science of climate change. Cambridge University press.

Ozor, N; Madukwe, M.C; Onokala P.C; Enete A; Garforth C.J; Eboh E.C; Ujah O. and Amaechina, E. (2010) A framework for agricultural adaptation to climate change in southern Nigeria. A Development Partnerships in Higher Education (DelPHE) 326 Project Executive Summary, supported by DFID and the British Council, Enugu: African Institute for Applied Economics.

Warrick R.A. and E.M. Barrow (1991) Climate change scenarios for the UK. Transactions of the Institute of British Geographers, 16:387-399.

Yan W. and M.S. Kang (2003) GGE biplot analysis: a graphical tool for breeders, geneticists and agronomists. CRC Press, Florida, U.S.A. 